\title{
Properties of a cryptic lysyl oxidase from haloarchaeon Haloterrigena turkmenica
}

\author{
Nikolay B Pestov ${ }^{\text {Corresp., }}$ 1 ， Daniel V Kalinovsky ${ }^{1}$ ， Tatyana D Larionova ${ }^{1}$ ， Alia Z Zakirova ${ }^{1}$, Nikolai $\mathbf{N}$ Modyanov \\ ${ }^{2}$, Irina A Okkelman ${ }^{1}$, Tatyana V Korneenko \\ 1 Shemyakin-Ovchinnikov Institute of Bioorganic Chemistry, Moscow, Russia \\ 2 Department of Physiology and Pharmacology, University of Toledo, Toledo, $\mathrm{OH}$, United States of America \\ Corresponding Author: Nikolay B Pestov \\ Email address: korn@mail.ibch.ru
}

B ackground: Lysyl oxidases (LOX) have been extensively studied in mammals, whereas properties and functions of recently found homologues in prokaryotic genomes remain enigmatic. Methods: LOX open reading frame was cloned from Haloterrigena turkmenica in an E. coli expression vector. Recombinant Haloterrigena turkmenica lysyl oxidase (HTULOX) proteins were purified using metal affinity chromatography under denaturing conditions followed by refolding. Amine oxidase activity has been measured fluorometrically as hydrogen peroxide release coupled with the oxidation of 10-acetyl-3,7dihydroxyphenoxazine in the presence of horseradish peroxidase. Rabbit polyclonal antibodies were obtained and used in western blotting. Results: Cultured $H$. turkmenica has no detectable amine oxidase activity. HTU-LOX may be expressed in $E$. coli with a high protein yield. The full-length protein gives no catalytic activity. For this reason, we hypothesized that the hydrophobic $\mathrm{N}$-terminal region may interfere with proper folding and its removal may be beneficial. Indeed, truncated His-tagged HTU-LOX lacking the Nterminal hydrophobic signal peptide purified under denaturing conditions can be successfully refolded into an active enzyme, and a larger $\mathrm{N}$-terminal truncation further increases the amine oxidase activity. Refolding is optimal in the presence of $\mathrm{Cu}^{2+}$ at pH 6.2 and is not sensitive to salt. HTU-LOX is sensitive to LOX inhibitor 3-aminopropionitrile. HTULOX deaminates usual substrates of mammalian LOX such as lysine-containing polypeptides and polymers. The major difference between HTU-LOX and mammalian LOX is a relaxed specificity of the former. HTU-LOX readily oxidizes various primary amines including such compounds as taurine and glycine, benzylamine being a poor substrate. Of note, HTU-LOX is also active towards several aminoglycoside antibiotics and polymyxin. Western blotting indicates that epitopes for the anti-HTU-LOX polyclonal antibodies coincide with a high molecular weight protein in $H$. turkmenica cells. Conclusion: $H$. turkmenica contains a lysyl oxidase gene that was heterologously expressed yielding an 
active recombinant enzyme with important biochemical features conserved between all known LOXes, for example, the sensitivity to 3-aminopropionitrile. However, the native function in the host appears to be cryptic. Significance: This is the first report on some properties of a lysyl oxidase from Archaea and an interesting example of evolution of enzymatic properties after hypothetical horizontal transfers between distant taxa. 


\section{Properties of a cryptic lysyl oxidase from haloarchaeon}

\section{Haloterrigena turkmenica}

\section{Nikolay B. Pestov ${ }^{1, *}$, Daniel V. Kalinovsky ${ }^{1}$, Tatyana D. Larionova ${ }^{1}$, Alia Z. Zakirova1,} Nikolay N. Modyanov², Irina A. Okkelman', Tatyana V. Korneenko1

${ }^{1}$ Shemyakin-Ovchinnikov Institute of Bioorganic Chemistry, Moscow, Russia

${ }^{2}$ Department of Physiology and Pharmacology, University of Toledo, Toledo, OH, United States of America

\section{Short title: Archaeal Lysyl Oxidase}

* To whom correspondence should be addressed: Nikolay B. Pestov, Shemyakin and Ovchinnikov Institute of Bioorganic Chemistry, Miklukho-Maklaya 16/10, Moscow, 117997, Russia, Tel: +7(495) 330-6556; Fax: +7(495) 330-6556; E-mail: korn@mail.ibch.ru

ABSTRACT

Background: Lysyl oxidases (LOX) have been extensively studied in mammals, whereas properties and functions of recently found homologues in prokaryotic genomes remain enigmatic. Methods: LOX open reading frame was cloned from Haloterrigena turkmenica in an E. coli expression vector. Recombinant Haloterrigena turkmenica lysyl oxidase (HTU-LOX) proteins were purified using metal affinity chromatography under denaturing conditions followed by refolding. Amine oxidase activity has been measured fluorometrically as hydrogen peroxide release coupled with the oxidation of 10-acetyl-3,7-dihydroxyphenoxazine in the presence of horseradish peroxidase. Rabbit polyclonal antibodies were obtained and used in western blotting. Results: Cultured H. turkmenica has no detectable amine oxidase activity. HTU-LOX may be expressed in $E$. coli with a high protein yield. The full-length protein gives no catalytic activity. For this reason, we hypothesized that the hydrophobic N-terminal region may interfere with proper folding and its removal may be beneficial. Indeed, truncated His-tagged HTU-LOX lacking the N-terminal hydrophobic signal peptide purified under denaturing conditions can be 
successfully refolded into an active enzyme, and a larger $\mathrm{N}$-terminal truncation further increases the amine oxidase activity. Refolding is optimal in the presence of $\mathrm{Cu}^{2+}$ at $\mathrm{pH} 6.2$ and is not sensitive to salt. HTU-LOX is sensitive to LOX inhibitor 3-aminopropionitrile. HTU-LOX deaminates usual substrates of mammalian LOX such as lysine-containing polypeptides and polymers. The major difference between HTU-LOX and mammalian LOX is a relaxed specificity of the former. HTU-LOX readily oxidizes various primary amines including such compounds as taurine and glycine, benzylamine being a poor substrate. Of note, HTU-LOX is also active towards several aminoglycoside antibiotics and polymyxin. Western blotting indicates that epitopes for the anti-HTU-LOX polyclonal antibodies coincide with a high molecular weight protein in H. turkmenica cells. Conclusion: H. turkmenica contains a lysyl oxidase gene that was heterologously expressed yielding an active recombinant enzyme with important biochemical features conserved between all known LOXes, for example, the sensitivity to 3-aminopropionitrile. However, the native function in the host appears to be cryptic. Significance: This is the first report on some properties of a lysyl oxidase from Archaea and an interesting example of evolution of enzymatic properties after hypothetical horizontal transfers between distant taxa.

\section{INTRODUCTION}

Lysyl oxidase is an amine oxidase that is well characterized in mammals. The human genome contains five lysyl oxidase isoforms (LOX and LOXL1-4), all of them possess the highly conserved C-terminal catalytic domain, the N-terminal signal peptide, and the accessory segments in between. Catalytic domain of LOX is unique among other mammalian amine oxidases because of its ability to oxidatively deaminate various amines including $\varepsilon$-amino groups of lysine residues in peptides and proteins. LOX activity initiates cross-link formation between certain proteins, including elastin, collagen, and fibronectin, and this process is important for maturation and remodeling of the extracellular matrix (Lucero and Kagan, 2006). Most animal genomes sequenced to date contain from one to five LOX genes, only placozoans, nematodes and ctenophores seem to lack any LOX genes. (Grau-Bove et al, 2015). There are LOX genes in some fungal genomes, whereas plants are unknown to possess it. LOX genes are also absent from the vast majority of prokaryotic genomes. Therefore, the presence of true homologues of 
62

63

64

65

66

67

68

69

70

animal LOX in just several species of Eubacteria and Archaea is of significant interest; it reflects the unique history of this enzyme, that most parsimoniously can be explained by multiple horizontal transfer events (HGT) (Grau-Bove et al, 2015). Among Eubacteria, LOX genes are frequent in Actinomycetes (especially Streptomyces), some Deltaproteobacteria, occasionally in other eubacteria, and very rarely - among Archaea. This aspect is exciting not only from the phylogenetic point of view, but also because of potential biotechnological applications, i.e. the fact that distantly related enzymes may have useful properties (Noda-García et al, 2013). It is interesting to note that, in contrast to eukaryotic lysyl oxidases, several LOX homologues identified in prokaryotes exhibit a simple architecture even without a signal peptide (Grau-Bove et al, 2015). On the other hand, some prokaryotic LOXes are more complex. Specifically, LOX from Sorangium cellulosum (WP_012233967.1) possesses a unique Cys-rich C-terminal noncatalytic domain, which is presumably highly disulfide cross-linked.

The few lysyl oxidase homologues from Archaea that have been sequenced are clustered in two independent groups. This suggests that the two major phyla, Thaumarchaeotes and Euryarchaeotes, may had acquired LOX genes in two independent HGT events (Grau-Bove et al, 2015). Indeed, HGT is widespread in Archaea (Papke et al, 2004, Papke et al, 2015).

Haloterrigena turkmenica was isolated from Turkmenistani sulfate saline soil by Zvyagintseva and Tarasov and described in 1987 as Halococcus turkmenicus (Zvyagintseva and Tarasov, 1987). In 1999 it was proposed to rename it to Haloterrigena (Ventosa et al, 1999). H. turkmenica belongs to the family Halobacteriaceae typus Euryarchaeota and is a fairly fast growing chemoorganotrophic extreme halophile that requires at least $2 \mathrm{M} \mathrm{NaCl}$ with optimal temperature around $45^{\circ} \mathrm{C}$. The complete genome of this archaeon has been sequenced. It consists of 5,440 kbp (including plasmid 6), and it was annotated as encoding 5,287 proteins and 63 ncRNAs (Saunders et al, 2010).

Here, we attempted for the first time a study on the properties of lysyl oxidase from this haloarchaeon.

\section{EXPERIMENTAL PROCEDURES}


90

91

92

93

94

95

96

97

100

101

102

103

104

105

106

107

108

109

110

111

112

113

114

115

116

117

118

119

Materials and strains. A fresh stock of Haloterrigena turkmenica VKMB-1734 was purchased from the All-Russian Collection of Microorganisms (G.K. Skryabin Institute of Biochemistry and Physiology of Microorganisms, Pushchino, Moscow Region, Russia). Capreomycin was from S.P. Incomed (Moscow, Russia), amikacin from OAO Sintez (Kurgan, Russia), substance P was custom synthesized at Syneuro (Moscow, Russia), hexylamine and 3-aminopropionitrile fumarate from Alfa Aesar (USA), all other amine substrates were from Sigma (USA).

Cultivation of H. turkmenica. Various haloarchaeal media with $\mathrm{NaCl}$ around $200 \mathrm{~g} / 1$ such as INMI medium-3, DSMZ-372 are suitable. Care should be taken to adjust pH since H. turkmenica does not grow in acidic media. We found that a simpler medium (hereafter referred to as IAO) is a better choice: casamino acids, $5 \mathrm{~g} / \mathrm{l}$; yeast extract, $5 \mathrm{~g} / \mathrm{l}$; NaCl, $220 \mathrm{~g} / \mathrm{l} ; \mathrm{pH} 7.6$ - autoclaved and supplemented with $\mathrm{MgSO}_{4}, 5 \mathrm{mM} ; \mathrm{CuCl}_{2}, 10 \mu \mathrm{M}$. Solid IAO medium may be used for growing single colonies, however, only with high quality agar (some batches inhibit growth). Also, $H$. turkmenica can be easily adapted to a defined medium, hereafter referred to as MHTU, an enriched version of HMM (Mosin and Ignatov, 2014)): L-alanine, 0.4 g/l; L-arginine, 0.4 g/l; Dasparagine, 0.2 g/l; L-aspartic acid, 0.4 g/l; L-cysteine, 0.1 g/l; L-glutamic acid, 1.5 g/l; L-histidine, 0.7 g/l; L-isoleucine, 0.5 g/l; L-leucine, 0.8 g/l; D,L-lysine, 2 g/l; D,L-methionine, 0.4 g/l; L-phenylalanine, 0.3 g/l; L-proline, 0.4 g/l; D,L-serine, 0.6 g/l; L-threonine, 1 g/l; L-tyrosine, 0.2 g/l; D,.L-tryptophan, $0.5 \mathrm{~g} / \mathrm{l} ; \mathrm{L}-$ valine, $1 \mathrm{~g} / \mathrm{l} ; \mathrm{AMP}, 0.1 \mathrm{~g} / \mathrm{l} ; \mathrm{NaCl}, 220 \mathrm{~g} / \mathrm{l} ; \mathrm{MgSO}_{4} \cdot 7 \mathrm{H}_{2} \mathrm{O}, 20 \mathrm{~g} / \mathrm{l} ; \mathrm{KCl}, 2 \mathrm{~g} / \mathrm{l} ; \mathrm{NH}_{4} \mathrm{Cl}, 0.5 \mathrm{~g} / \mathrm{l}$; $\mathrm{KNO}_{3}, 0.1 \mathrm{~g} / \mathrm{l} ; \mathrm{KH}_{2} \mathrm{PO}_{4}, 0.1 \mathrm{~g} / \mathrm{l} ; \mathrm{K}_{2} \mathrm{HPO}_{4}, 0.1 \mathrm{~g} / \mathrm{l} ; \mathrm{Na}_{3} \cdot$ citrate, $0.8 \mathrm{~g} / \mathrm{l} ; \mathrm{MnSO}_{4} \cdot 2 \mathrm{H}_{2} \mathrm{O}, 0.0003 \mathrm{~g} / \mathrm{l}$; $\mathrm{CaCl}_{2} \cdot 6 \mathrm{H}_{2} \mathrm{O}, 0.1 \mathrm{~g} / \mathrm{l} ; \mathrm{ZnSO}_{4} \cdot 7 \mathrm{H}_{2} \mathrm{O}, 0.05 \mathrm{mg} / \mathrm{l} ; \mathrm{FeSO}_{4} \cdot 7 \mathrm{H}_{2} \mathrm{O}, 0.05 \mathrm{~g} / \mathrm{l} ; \mathrm{CuCl}_{2}, 10 \mu \mathrm{M}$; glycerol, $1 \mathrm{~g} / \mathrm{l}$; Dleucine-OH, $0.1 \mathrm{~g} / \mathrm{l}$; norleucine, $0.1 \mathrm{~g} / \mathrm{l}$; thymine, $0.1 \mathrm{~g} / \mathrm{l}$; uracil, $0.1 \mathrm{~g} / \mathrm{l} ; \mathrm{pH}$ 7.5.

Isolation of Halorubrum sp. VKK1262. Commercial salt from Upper-Kama deposit (Uralmedprom, Berezniki, Russia) was mixed with IAO medium without $\mathrm{NaCl}$ (200 g/l) and filtered through a $0.2 \mu \mathrm{m}$ GSWP filter (Millipore, USA). Filters were incubated on IAO medium plates prepared with Noble agar (Difco, USA) at $37^{\circ} \mathrm{C}$ for one week and colored colonies were restreaked several times on fresh plates. 16S RNA sequence was analyzed using PCR with primers Arch16S-f2 and Arch16S-r934 and Sanger sequencing of the amplicons in both directions.

Gene cloning. The DNA used as a template for PCR was isolated from the cell culture using a ZR Fungal / Bacterial DNA MicroPrep kit (Zymo Research, USA) according to the manufacturer's 
120 instructions. For PCR, in an equal volume of $25 \mu 1$, primers (sequences in Supplement) at a

121 concentration of $0.8 \mu \mathrm{M}$, PCR buffer 5x Phusion GC reaction buffer, $2 \mu 12.5 \mathrm{mM}$

122 deoxyribonucleotide solution, $0.2 \mu$ of Phusion DNA polymerase, and $H$. turkmenica genomic

123 DNA as a template were used. The cycling parameters were as follows: 1 . Hot start $98^{\circ} \mathrm{C}$ for 2 min;

124 2. Denaturation at $98^{\circ} \mathrm{C}, 30 \mathrm{~s} ; 3$. Annealing at $55^{\circ} \mathrm{C}, 1 \mathrm{~min} ; 4$. Elongation at $72^{\circ} \mathrm{C}, 2 \mathrm{~min} .30$ cycles

125 between steps 4 and 2. 5. Final elongation at $72^{\circ} \mathrm{C}$ for $7 \mathrm{~min}$. Purified polynucleotide fragments

126 HTU-AA and HTU-QV (AA and QV stand for corresponding dipeptides in the HTU-LOX

127 sequence) were digested with Bam H I and Hind III restriction enzymes and ligated into the

128 corresponding sites of the pQE-30 vector (Qiagen, USA), followed by transformation of the E. coli

129 strain XL1-Blue by electroporation. Colonies screening was performed by PCR, and the sequence

130 was confirmed by Sanger sequencing.

131 Protein expression. The XL-1 Blue transformants HTU-AA and HTU-QV were grown in LB

132 medium containing ampicillin on an orbital shaker at $37^{\circ} \mathrm{C}$ until $\mathrm{OD}_{600}=0.7$ was reached, followed

133 by induction of expression with $0.5 \mathrm{mM}$ IPTG for 3 hours. The cells were then harvested by

134 centrifugation and stored at $-70^{\circ} \mathrm{C}$. His-tagged proteins were purified under denaturing conditions $(8$

$135 \mathrm{M}$ urea) on the metal-chelating sorbent Ni-NTA agarose (Korneenko and Pestov, 1997). Typical

136 yields of the purified proteins HTU-QV and HTU-AA were around 25-27 mg per liter of culture.

137 The resulting proteins in $8 \mathrm{M}$ urea $\mathrm{pH} 6.3$ buffered with $0.5 \mathrm{M}$ imidazole, $0.1 \mathrm{M}$ sodium phosphate,

138 and $20 \mathrm{mM}$ Tris were dialyzed against different buffers (optimization briefly described in Results).

Activity assays. Determination of substrate specificity was performed using a fluorometric method suitable for various amine oxidases as the release of hydrogen peroxide coupled to the oxidation of 10-acetyl-3,7-dihydroxyphenoxazine (Biotium, Germany), also known as Amplex red, in the presence of horseradish peroxidase (Palamakumbura and Trackman, 2002). The fluorescence of the reaction product (resorufin) was assayed with a Microplate analyzer "Fusion" (Perkin Elmer, USA) at excitation and emission of 535 and $620 \mathrm{~nm}$, respectively. More specifically, the reaction was carried out in $0.1 \mathrm{M}$ borate buffer $\mathrm{pH} 8.3$ in the presence of $1 \mathrm{U} / \mathrm{ml}$ horseradish peroxidase at $37^{\circ} \mathrm{C}, 100 \mu \mathrm{l}$ volume and $0.5-5 \mu \mathrm{g}$ purified protein (up to $50 \mu \mathrm{g}$ protein for crude lysates). For the negative control, $0.1 \mathrm{mM} 3$-aminopropionitrile was added to block any lysyl oxidase activity. 
150 Michaelis-Menten equation using Prism software package (GraphPad, USA). Sheep LOX was

151 isolated from aorta as described before for the purpose of comparison with HTU-LOX (Pestov et al, 152 2014).

153 Immunization of rabbits was carried out with purified folded protein HTU-QV. Initially, rabbits 154 were subcutaneously injected with $100 \mu \mathrm{g}$ protein as an emulsion in Freund's complete adjuvant. 155 The first booster injection was made with the same quantity of the antigen in incomplete Freund's 156 adjuvant 5 weeks after the first immunization, and the second booster injection - with $250 \mu \mathrm{g}$ 157 antigen and no adjuvants 6 weeks later. One week after the second booster injection sera were 158 collected and stored with the preservative sodium azide at $4^{\circ} \mathrm{C}$. Immunization of rabbits has been 159 approved by Animal Care and Use Review Board of Shemyakin-Ovchinnikov Institute of 160 Bioorganic Chemistry, protocol No 15/2011.

161

162

163

164

165

166

167

168

169

170

171

172

173

174

175

176

177

178

179

Affinity purification of antibodies has been performed on a small-scale essentially as before (Pestov et al, 2004) using purified HTU-QV protein electrophoresed using SDS-PAGE and blotted on a PVDF membrane: the HTU-QV band on PVDF was blocked in TBST buffer containing 5\% bovine serum albumin and 5\% non-fat milk, then serum was added and incubated for $3 \mathrm{~h}$. After several washes with TBST bound antibodies were eluted with $0.1 \mathrm{M}$ sodium citrate ( $\mathrm{pH} 2.0)$ for 10 min at followed by immediate neutralization with unbuffered tris and addition of $0.1 \%$ bovine serum albumin and $0.02 \%$ sodium azide.

Western blotting. H. turkmenica cells were centrifuged and the pellets were lyzed in $10 \mathrm{mM}$ tris$\mathrm{HCl}, 1 \mathrm{mM} \mathrm{MgCl}$, $\mathrm{pH} 7.5$ containing $0.5 \mathrm{mM}$ tris(2-carboxyethyl)phosphine (Sigma, USA), Complete protease inhibitor cocktail (Roche, Switzerland) and $1 \mathrm{u} / \mathrm{ml}$ Benzonase (EMD Millipore, USA) for $15 \mathrm{~min}$ at $37^{\circ} \mathrm{C}$ followed by centrifugation for $10 \mathrm{~min}$ at $15000 \mathrm{~g}$. The supernatants were mixed with Laemmli sample loading buffer without mercaptoethanol and analyzed by electrophoresis in 8\% SDS PAGE gels. Following electrophoresis, the protein samples and colored protein weight markers (Spectra Multicolor Brad Range, Thermo, USA) were transferred from polyacrylamide gel onto a PVDF membrane (GE Healthcare, USA). The membrane was washed for 5 min with $2 \%$ SDS, then blocked in TBST buffer containing 5\% non-fat milk, $0.02 \%$ sodium azide and $10 \% \mathrm{w} / \mathrm{w}$ Bløk blocker (EMD Millipore, USA), overnight at $4^{\circ} \mathrm{C}$. On the next stage, the membrane was incubated in $10 \mathrm{ml}$ of TBST buffer solution with $0.1 \%$ non-fat dry milk and primary rabbit antibodies (1:10000) for one hour at room temperature, rinsed out with TBST buffer 10 times 
180 for 5 minutes each, followed by incubation with secondary antibodies (HRP-conjugated anti-rabbit 181 antibodies, Biotium, Germany, 1:50000) in $10 \mathrm{ml} \mathrm{TBST}$ buffer with $0.1 \%$ non-fat dry milk for one 182 hour, and rinsed out again in the same way. Chemiluminescence was recorded using Femto 183 Maximum Sensitivity Western Blotting Detection Reagent (Thermo, USA) and Carestream Kodak 184 Biomax Light film (Sigma, USA).

185

186

187

188

189

190

191

192

193

194

195

196

197

198

199

200

201

202

203

204

205

206

207

208

209

\section{RESULTS}

We initially attempted to produce the full-length HTU-LOX protein in E. coli but found that it precipitates as inclusion bodies without any detectable amine oxidase activity (Supplement), and all attempts at its refolding were unsuccessful (results not shown). For this reason, we proceeded to truncations without the N-terminal peptide (hydrophobic segments are common sources of problematic expression in E. coli) with subsequent purification under denaturing conditions and refolding. The purity of the resulting eluate was checked by SDS PAGE. Fig. 1 illustrates the expression and purification of HTU-LOX exemplified by HTU-QV variant. Of note is the fact of its anomalously slow electrophoretic mobility that corresponds to an apparent molecular weight of $34 \mathrm{kDa}$, whereas the theoretical value of the His-tagged HTU-QV is $24.3 \mathrm{kDa}$. Since HTULOX is a rather acidic protein (theoretical pI 4.58 for the His-tagged HTU-QV and 4.09 for the full-length protein), this peculiarity is common among acidic proteins (García-Ortega et al, 2005).

Refolding of the purified his-tagged proteins HTU-AA ( $\Delta 1-34)$ and HTU-QV ( $\Delta 1-91)$ was achieved using dialysis against different buffers and results in good amine oxidase activity. We investigated a variety of factors that may improve the formation of catalytically active proteins HTU-AA and HTU-QV: buffer type and concentration (Tris, phosphate buffered saline, acetate, etc.), the ionic strength of the solution (concentration of $\mathrm{NaCl})$, temperature, metal ions $(\mathrm{Cu}, \mathrm{Fe}$, $\mathrm{Zn}, \mathrm{Ni}, \mathrm{Co}, \mathrm{Mn})$ in different concentrations, $\mathrm{pH}$ of the solution $(5.0-8.0)$, as well as the dialysis with a gradual decrease in the concentration of the denaturing agent (urea). Optimal $\mathrm{pH}$ is around 6.2 (Fig. 2A). Since it is known that mammalian LOX requires the presence of a copper ion in the catalytic domain in order to achieve the formation of the lysyl-tyrosine quinone (LTQ) in the catalytic center, we expected similar results of for HTU-LOX. Indeed, only $\mathrm{Cu}^{2+}$ increases activity (Fig. 2B,C), whereas a mixture of different ions gives an inhibition (Fig. 2C). It is interesting to note that refolding efficiency is only slightly affected by $\mathrm{NaCl}$ concentration, 
210 contrary to the expectations from the fact that $H$. turkmenica is an extreme halophile that requires

211 at least $2 \mathrm{M} \mathrm{NaCl}$ (Fig. 2B). In the case of $\mathrm{NaCl}$ similar results were obtained in folding by

212 dilution experiments, demonstrating also that $1 \mathrm{M}$ and $2 \mathrm{M} \mathrm{NaCl}$ cannot improve activity any

213 further (results not shown).

214 A slow decrease of the denaturant (urea) concentration was found to lack any advantages over

215 the stepwise approach with immediate transfer into a buffer without urea. This was confirmed by

216 refolding by dilution (results not shown). Ultimately, a simple refolding procedure may be

217 considered as optimal:

218 - Dialysis against $40 \mathrm{mM}$ sodium acetate, $\mathrm{pH} 6.2$ with $1 \mathrm{mM} \mathrm{CuSO}_{4}$ at $4^{\circ} \mathrm{C}$ for 3 hours;

219 - Dialysis against $40 \mathrm{mM}$ sodium acetate, pH 6.2 without copper at $4^{\circ} \mathrm{C}$ overnight.

220

221 Interestingly, under any conditions used, the amine oxidase activity of the protein HTU-QV AA

222 (typical activity for HTU-QV with $1 \mathrm{mM}$ taurine at $\mathrm{pH} 8.3$ was approximately $0.014 \mu \mathrm{mole} / \mathrm{min}$

223 hydrogen peroxide per·mg protein) was about fifteen times higher than that of HTU-AA.

224 Therefore, the segment of HTU-LOX sequence from $\mathrm{Ala}^{35}$ to $\mathrm{Gln}^{92}$ may function as an inhibitory

225 (pro)peptide or just interferes during refolding.

226 Refolded proteins HTU-QV and HTU-AA exhibit activity against a wide variety of primary

227 amines (Table 1): histamine, methylamine, lysine, cadaverine, tyramine, etc. Even glycine, $\beta$ -

228 alanine are efficiently oxidized, in contrast with mammalian LOX. HTU-LOX readily oxidizes

229 some amine-containing antibiotics: polymyxin and aminoglycosides such as capreomycin and

230 amikacin. This is a unique property of lysyl oxidases, since other amine oxidases either do not

231 deaminate aminoglycosides or even are inhibited by them, as in the case of E. coli amine oxidase

232 (Elovaara et al, 2015). Regarding various proteins, lysine-containing peptides, and polymers

233 (e.g., poly-L-lysine, poly-allylamine, lysozyme, and substance P as an example of a Lys-

234 containing peptide), the HTU-LOX behaves almost like LOX from the aorta. Taurine is one of

235 the best substrates for HTU-LOX. It is also capable of oxidizing glycine, $\beta$-alanine, and $\gamma$ -

236 aminobutyric acid. The only amine that HTU-LOX oxidizes much worse than mammalian LOX

237 is benzylamine. Importantly, the HTU-LOX demonstrated good sensitivity to the classical

238 inhibitor of all LOXes - 3-aminopropionitrile (BAPN). Also, HTU-LOX is somewhat different

239 from the mammalian enzyme in terms of $\mathrm{pH}$ dependence. In contrast to the latter, HTU-LOX 
240 activity does not exhibit a steep decline from its maximum around 8.3, and even displays a

241 certain degree of bimodality retaining some activity even below 7 (Fig. 3).

242 We also attempted to study the HTU-LOX protein in the host - the archaeal halophile $H$.

243 turkmenica. For this purpose, we raised polyclonal antibodies against the truncated HTU-LOX

244 (variant QV). The full-size HTU-LOX theoretically contains 308 amino acids with a molecular

245 weight of $33829 \mathrm{Da}$, whereas the full-length protein expressed in E. coli has electrophoretic

246 mobility corresponding to $52 \mathrm{kDa}$ (Suppl. Fig.). However, this apparently large discrepancy

247 should be regarded as normal, since the anomalous mobility has been observed for purified

248 recombinant HTU-LOX (Fig. 1). Western blotting indicates that HTU-LOX may be present in $H$.

249 turkmenica cells (Fig. 4, lanes 1-2, compare to negative controls in lanes 3-6, where lanes 4-6

250 show non-specific binding of unrelated antibodies plus secondary antibodies, and lanes 3 and 6

251 provide an additional negative control - non-specific binding of antibodies to proteins from

252 Halorubrum, a totally different haloarchaeal species). It should be emphasized that specific

253 bands were detected only at a high sensitivity, meaning that the normal expression level of the

254 protein in cultured H. turkmenica is quite low, and detection of the full-length, unprocessed

255 HTU-LOX was obscured by non-specific bands (Fig. 4, lanes 4-5). Most interestingly, only a

256 very high molecular weight band specific to anti-HTU-LOX antibodies of about $210 \mathrm{kDa}$ has

257 been reliably detected. Importantly, this band is certainly absent from the Halorubrum sample

258 (Fig. 4, lane 3), where any HTU-LOX should be absent a priori. Prolonged incubation of the

259 cells in saturated salt in the medium results in a marked decrease in the intensity of this band

260 (Suppl. Fig.). Therefore, we can hypothesize that HTU-LOX in H. turkmenica predominantly

261 exists in a moderately stable homo- or heterooligomeric form, which migration in SDS-PAGE

262 corresponds to an apparent molecular weight of $210 \mathrm{kDa}$, however, this anomaly awaits further

263 studies.

264 Also, we found that BAPN (even at a rather high concentration of $1 \mathrm{mM}$ ) had no significant

265 effect on sensitivity of fresh cells to osmotic stress, on formation of hypotonically-resistant cysts,

266 or on growth rate in both conventional (IAO) and defined (MHTU) media.

\section{DISCUSSION}


268 Amino acid sequence alignments (Fig. 5-6) of LOX proteins demonstrate poor overall

269 conservation (for example, high variability in the number of disulfide bonds) with only a few

270 hyperconserved amino acid residues like Cu-binding His and LTQ formation (Zhang et al,

271 2018). A fundamental aspect that needs to be emphasized is the fact that relatively little research

272 has been carried out on the influence of HGT with the subsequent adaptation of the catalytic

273 properties of the enzymes to a new host.

274 Refolding efficiency is not significantly affected by $\mathrm{NaCl}$ concentration. This surprising fact

275 could reflect the history of prokaryote LOX genes: halophile archaea may have acquired these

276 genes from microorganisms with a rather different requirement for salt. The ancient HGT event

277 may had even originated from a halophobic organism, followed by "domestication" that

278 suppressed the formation of misfolded protein. Besides, LOX may had served as an antibiotic

279 resistance enzyme under aerobic conditions. This, however, is unlikely in extant $H$. turkmenica,

280 since Archaea are usually highly resistant to both polymyxin and common aminoglycosides.

281 Also, HTU-LOX oxidizes some peptide antibiotics and theoretically this feature may be useful

282 for competition with other species of haloarchaea (Besse et al, 2015) in the natural habitat of $H$.

283 turkmenica. The low expression level of the enzyme suggests that HTU-LOX plays a modest

284 functional role in increasing availability of nitrogen from non-typical amines. Its promiscuous

285 substrate specificity and negligible enzymatic activity in H. turkmenica cells (Supplement) make

286 it difficult to demonstrate this fact experimentally.

287 HTU-LOX accepts glycine, $\beta$-alanine, and $\gamma$-aminobutyric acid as substrates. This observation is

288 unusual, because the presence of any acidic groups in vicinity of the amino group almost

289 completely prevents oxidation by most amine oxidases. Thus, it is safe to conclude that the

290 HTU-LOX has a relaxed substrate specificity in comparison with its mammalian homologue

291 (Shah et al, 1993). Perhaps a low selection pressure on the lysyl oxidase gene allowed it to lose

292 substrate specificity. This, however, may be useful for biotechnological purposes as a starting

293 point for molecular evolution in any direction.

294 Another interesting fact is that the amine oxidase activity of the truncated protein HTU-QV is

295 much higher than that of the longer one, HTU-AA. This observation is in line with the general

296 view that LOX catalytic domain is usually (except for animal LOXL2-4 and homologs) preceded

297 by an autoinhibitory sequence, together forming a propeptide. In the case of HTU-LOX, the 
298 autoinhibitory sequence corresponds to the stretch from $\mathrm{Ala}^{39}$ to $\mathrm{Gln}^{92}$. However, the inhibition

299 is relatively inefficient, and this may also reflect the evolution of HTU-LOX gene after the in-

300 Archaea HGT that resulted in a partial degradation of the autoinhibitory function of the

301 propeptide. LOX genes in Archaea underwent at least two independent HGTs (Grau-Bove et al,

302 2015) and this is just an example of HGT in Archaea (Papke et al, 2004, Papke et al, 2015). The

303 widespread occurrence of these HGT events may also indicate that the transferred genes not

304 necessarily possess indispensable functions in every species.

305 Immunoblotting experiments allow us to hypothesize that HTU-LOX in H. turkmenica

306 predominantly exists in a moderately stable homo- or heterooligomeric form, which migration in

307 SDS-PAGE corresponds to an apparent molecular weight of $210 \mathrm{kDa}$. This anomaly awaits

308 further studies but may have interesting implications, for example, explain lack of detectable

309 amine oxidase activity in Haloterrigena cells.

310 What is the origin of the animal lysyl oxidase? Has it emerged in primitive animals at the

311 beginning of their evolution through HGT from Eubacteria? Or, conversely, LOX genes, which

312 have important functions in animals, made their way several times into the world of prokaryotes?

313 The second option seems highly unlikely due to splitting of animal ORFs into exons and

314 molecular phylogeny (Grau-Bové et al, 2015) but cannot be excluded completely. In any respect,

315 the most parsimonious explanation of the evolution of the catalytic LOX domain is that inter-

316 kingdom saltations of LOX genes between distant branches of Life occurred more than once.

\section{CONCLUSIONS}

318

319

320

321

322

323

324

325

H. turkmenica LOX (HTU-LOX) was successfully expressed in E. coli. Optimal refolding conditions are different from those for the growth of the host cells. HTU-LOX has a relaxed substrate specificity in comparison with mammalian LOX, benzylamine is a poor substrate for both, and sensitivity to 3-aminopropionitrile is conserved in HTU-LOX. N-terminal truncation of HTU-LOX increases its activity. Cultured H. turkmenica does not exhibit any detectable amine oxidase activity, and expression level of the HTU-LOX is low. Therefore, native function of $H$. turkmenica lysyl oxidase may be cryptic.

\section{ACKNOWLEDGMENTS}




\section{REFERENCES}

328

Besse A, Peduzzi J, Rebuffat S, Carré-Mlouka A. 2015. Antimicrobial peptides and proteins in the face of extremes: Lessons from archaeocins. Biochimie 118: 344-355.

Dmitriev RI, Okkelman IA, Abdulin RA, Shakhparonov MI, Pestov NB. 2009. Nuclear transport of protein TTC4 depends on the cell cycle. Cell Tissue Res 336: 521-527. García-Ortega L, De los Ríos V, Martínez-Ruiz A, Oñaderra M, Lacadena J, Martínez del

Pozo A, Gavilanes JG. 2005. Anomalous electrophoretic behavior of a very acidic protein: ribonuclease U2. Electrophoresis. 26: 3407

Grau-Bové X, Ruiz-Trillo I, Rodriguez-Pascual F. 2015. Origin and evolution of lysyl oxidases. Scientific Reports 5: 10568 coli is a metabolic enzyme that can use a human leukocyte molecule as a substrate. PLOS One 10: $\mathrm{e} 0142367$

Lucero HA, Kagan HM. 2006. Lysyl oxidase: an oxidative enzyme and effector of cell function. Cellular and Molecular Life Sciences 63: 2304-2316

Korneenko TV, Pestov NB, Egorov MB, Ivanova MV, Kostina MB, Shakhparonov MI. 1997. Monoclonal antibodies to the $\alpha$-subunit of the putative human $\mathrm{H}^{+}, \mathrm{K}^{+}$-ATPase encoded by the atp1all gene. Bioorganicheskaya khimiya 23: 800-8004.

Mosin O, Ignatov, I. 2014. Photochrome Transmembrane Protein Bacteriorhodopsin from Purple Membranes of Halobacterium halobium. Applications in Bio- and Nanotechnologies. Journal of Medicine, Physiology and Biophysics 6: 42-60

Noda-García L, Camacho-Zarco AR, Medina-Ruíz S, Gaytán P, Carrillo-Tripp M, Fülöp V,

Barona-Gómez F. 2013. Evolution of substrate specificity in a recipient's enzyme following horizontal gene transfer. Molecular Biology and Evolution 30: 2024-2034

Palamakumbura AH, Trackman PC. 2002. A fluorometric assay for detection of lysyl oxidase enzyme activity in biological samples. Analytical Biochemistry 300: 245-251. 
357 Papke RT, Koenig JE, Rodríguez-Valera F, Doolittle WF. 2004. Frequent recombination in a 358 saltern population of Halorubrum. Science 306: 1928-1929.

359 Pestov NB, Korneenko TV, Radkov R, Zhao H, Shakhparonov MI, Modyanov NN. 2004.

360 Identification of the $\beta$-subunit for nongastric H-K-ATPase in rat anterior prostate. American 361 Journal of Physiology. Cell Physiology. 286: C1229-C1237.

362 Pestov NB, Okkelman IA, Shmanai VV, Hurski AL, Giaccia AJ, Shchepinov MS. 2011.

363 Control of lysyl oxidase activity through site-specific deuteration of lysine. Bioorganic \& 364 Medicinal Chemistry Letters 21: 255-258.

365 Saunders E, Tindall BJ, Fähnrich R, Lapidus A, Copeland A, Del Rio TG, Lucas S, Chen 366 F, Tice H, Cheng JF, Han C, Detter JC, Bruce D, Goodwin L, Chain P, Pitluck S, Pati A, 367 Ivanova N, Mavromatis K, Chen A, Palaniappan K, Land M, Hauser L, Chang YJ, Jeffries 368 CD, Brettin T, Rohde M, Göker M, Bristow J, Eisen JA, Markowitz V, Hugenholtz P, 369 Klenk HP, Kyrpides NC. 2010. Complete genome sequence of Haloterrigena turkmenica type 370 strain (4k). Standards in Genomic Sciences 2: 107-116.

371 Shah MA, Scaman CH, Palcic MM, Kagan HM. 1993. Kinetics and stereospecificity of the 372 lysyl oxidase reaction. Journal of Biological Chemistry 268: 11573-11579.

373 Ventosa A, Carmen Gutierrez M, Kamekura M, Dyall-Smith M L. 1999. Proposal to transfer 374 Halococcus turkmenicus, Halobacterium trapanicum JCM 9743 and strain GSL-11 to 375 Haloterrigena turkmenica gen. nov., comb. nov. International Journal of Systematic Bacteriology 376 49: 131-136.

377 Zhang X, Wang Q, Wu J, Wang J, Shi Y, Liu M. 2018. Crystal structure of human lysyl oxidase378 like 2 (hLOXL2) in a precursor state. Proceedings of the National Academy of Sciences of the 379 United States of America. 115: 3828-3833.

380 Zvyagintseva IS, Tarasov AL. 1987. Extreme halophilic bacteria from alkaline soils. 381 Mikrobiologiya 56: 839-844.

\section{FIGURE LEGENDS}

384

385

386

387
Table

Substrate efficiencies of recombinant Haloterrigena lysyl oxidase (HTU-QV variant) in comparison with mammalian enzymes from aorta. $V_{\max } / K_{m}$ ratios normalized with respect to tyramine. Values for polymers and lysozyme calculated per amine groups. Data for LOX from 
388 389

390 391

392

393 394 395

396

397 398

402

403

404

405

406

407

408

409

410

411

412

413

414

bovine aorta from (Shah et al, 1993) (note that conditions used were significantly different from this study). For HTU-LOX the short variant QV has been used. ND - no data. Z - rate too low for accurate determination. $\mathrm{CK}$ - complex kinetics with inhibition by substrate at high concentrations.

Figure 1. Electrophoretic analysis of expression and purification of recombinant Nterminally truncated $\boldsymbol{H}$. turkmenica LOX (HTU-QV). 1 - molecular weight marker proteins; 2 - E. coli proteins before addition of IPTG; 3 - expression induced with IPTG; 4 - purified HTUQV protein.

Fig. 2. Folding of recombinant $\boldsymbol{H}$. turkmenica lysyl oxidase (HTU-QV). Folding by dialysis. A - Influence of $\mathrm{pH} ; \mathrm{B}$ - effect of $\mathrm{NaCl} ; \mathrm{C}-1 \mathrm{mM}$ salts of various metals added to the dialysis buffer; $\mathrm{D}$ - different concentrations of $\mathrm{CuSO}_{4}$.

Fig. 3. pH dependence of recombinant $\boldsymbol{H}$. turkmenica lysyl oxidase. Amine oxidase reaction rates for HTU-QV protein in comparison with LOX from sheep aorta were measured in universal borate-phosphate-acetate buffer with histamine as the substrate.

Figure 4. Immunoblotting with anti-HTU-LOX antibodies and proteins from $\mathrm{H}$. turkmenica cells. Chemiluminescence of bound HRP-labeled antibodies; positions of molecular weight markers on the left and in the middle. 1-3 - affinity purified antibodies against HTU-QV, the catalytic domain of LOX from $H$. turkmenica. 4-6 - negative control with rabbit serum against an unrelated antigen (Dmitriev et al, 2009). 1,2,4,5 - proteins of H. turkmenica grown to log-phase (lanes 1 and 4 were loaded with three times more protein than lanes 2 and 5). 3,6-proteins of Halorubrum sp. VKK1262 (loading equal to lanes 2 and 5).

Fig. 5. Multiple alignment of archaeal lysyl oxidases. Obtained using Muscle algorithm. (HaloterrigenalimiCola - Haloterrigena limicola, HaloterrigenaturCk - Haloterrigena turkmenica, NatronoCoCCusjeotgali - Natronococcus jeotgali, NitrosopumilussalariaDB31 and Nitrosopimulus - Nitrosopumilus sequnces. Yellow - cysteine residues marked in yellow; red - 
415 LTQ-forming lysine and tyrosine; purple - three hyperconserved histidine residues necessary for 416 the binding of $\mathrm{Cu}^{2+}$.

417

418 Fig. 6. Multiple alignment of the conserved segments of catalytic domains from all lysyl 419 oxidases representing different kingdoms. Obtained using Muscle algorithm from consensus 420 sequences of different taxa. ARCHAE - Archaeal LOX sequences, DELTA 421 Deltaproteobacteria, FUNGI - fungal LOXes, ANIMA - various animal LOXes, LOW -

422 Mesomycetozoa and Orthonectida, short - LOX from Truepera radiovitrix, Deinococcus 423 pimensis, Nitrospira nitrosa, and a few samples from Parcubacteria, BETA -

424 Betaproteobacteria, Actinshort - Amycolatopsis mediterranei LOX and closest homologues, 425 STREPTOM - LOX from Streptomyces, ACTINvar - other actinomycetal LOXes, BACIES - all 426 other eubacterial LOXes. Yellow - cysteine residues marked in yellow; red - LTQ-forming 427 lysine and tyrosine; purple - three hyperconserved histidine residues necessary for the binding of 428 copper. 


\section{Table $\mathbf{1}$ (on next page)}

Substrate efficiencies of recombinant Haloterrigena lysyl oxidase (HTU-QV variant) in comparison with mammalian enzymes from aorta.

$\mathrm{V}_{\text {max }} / \mathrm{K}_{\mathrm{m}}$ ratios normalized with respect to tyramine. Values for polymers and lysozyme calculated per amine groups. Data for LOX from bovine aorta from (Shah et al, 1993) (note that conditions used were significantly different from this study). For HTU-LOX the short variant QV has been used. ND - no data. Z - rate too low for accurate determination. CK complex kinetics with inhibition by substrate at high concentrations. 
1

$\begin{array}{cccc}\text { substrate } & \text { HTU-LOX } & \text { Sheep } & \text { Bovine } \\ \text { L-lysine } & 0.058 & 0.028 & \mathrm{ND} \\ \text { cadaverine } & 0.370 & 1.070 & 1.09 \\ \text { histamine } & 0.550 & 0.920 & \mathrm{ND} \\ \text { taurine } & 1.120 & 0.120 & \mathrm{ND} \\ \text { glycine } & 0.020 & \mathrm{z} & \mathrm{ND} \\ \beta \text {-alanine } & 0.005 & \mathrm{z} & \mathrm{ND} \\ \text { GABA } & 0.015 & \mathrm{Z} & \mathrm{ND} \\ \text { methylamine } & 0.020 & \mathrm{ND} & \mathrm{ND} \\ \text { substance P } & 0.068 & \mathrm{ND} & \mathrm{ND} \\ \text { lysozyme } & \mathrm{CK} & 0.080 & \mathrm{ND} \\ \text { polyallylamine } & \mathrm{CK} & 0.080 & \mathrm{ND} \\ \text { amikacin } & 0.260 & \mathrm{ND} & \mathrm{ND} \\ \text { capreomycin } & 0.120 & 0.190 & \mathrm{ND} \\ \text { polymyxin } & 0.780 & \mathrm{ND} & \mathrm{ND} \\ \text { benzylamine } & \mathrm{z} & 0.170 & 0.52 \\ \text { hexylamine } & 0.28 & 1.140 & 0.14\end{array}$

2

3

4 Substrate efficiencies of recombinant Haloterrigena lysyl oxidase (HTU-QV variant) in

5 comparison with mammalian enzymes from aorta. $\mathrm{V}_{\mathrm{max}} / \mathrm{K}_{\mathrm{m}}$ ratios normalized with respect to

6 tyramine. Values for polymers and lysozyme calculated as for molar amine groups. Data for LOX

7 from bovine aorta from (Shah et al, 1993) (note that conditions used were significantly different

8 from this study). For HTU-LOX the short variant QV has been used. ND - no data. Z - rate too

9 low for accurate determination. CK - complex kinetics with inhibition by substrate at high

10 concentrations. 


\section{Figure 1}

Electrophoretic analysis of recombinant N-terminally truncated $\mathrm{H}$. turkmenica LOX (HTU-QV) expression and purification.

1 - molecular weight marker proteins; 2 - E. coli proteins before addition of IPTG; 3 Expression induced with IPTG; 4 - purified HTU-QV protein. 


\section{$\begin{array}{lllll}\mathrm{kDa} & 1 & 2 & 3 & 4\end{array}$ \\ 150}

100

70

50

40

30

20 
Figure 2

Folding of recombinant $H$. turkmenica lysyl oxidase (HTU-QV).

Folding by dialysis. A - Influence of $\mathrm{pH}$; $\mathrm{B}$ - effect of $\mathrm{NaCl} ; \mathrm{C}-1 \mathrm{mM}$ salts of various metals added to the dialysis buffer; $\mathrm{D}$ - different concentrations of $\mathrm{CuSO}_{4}$.
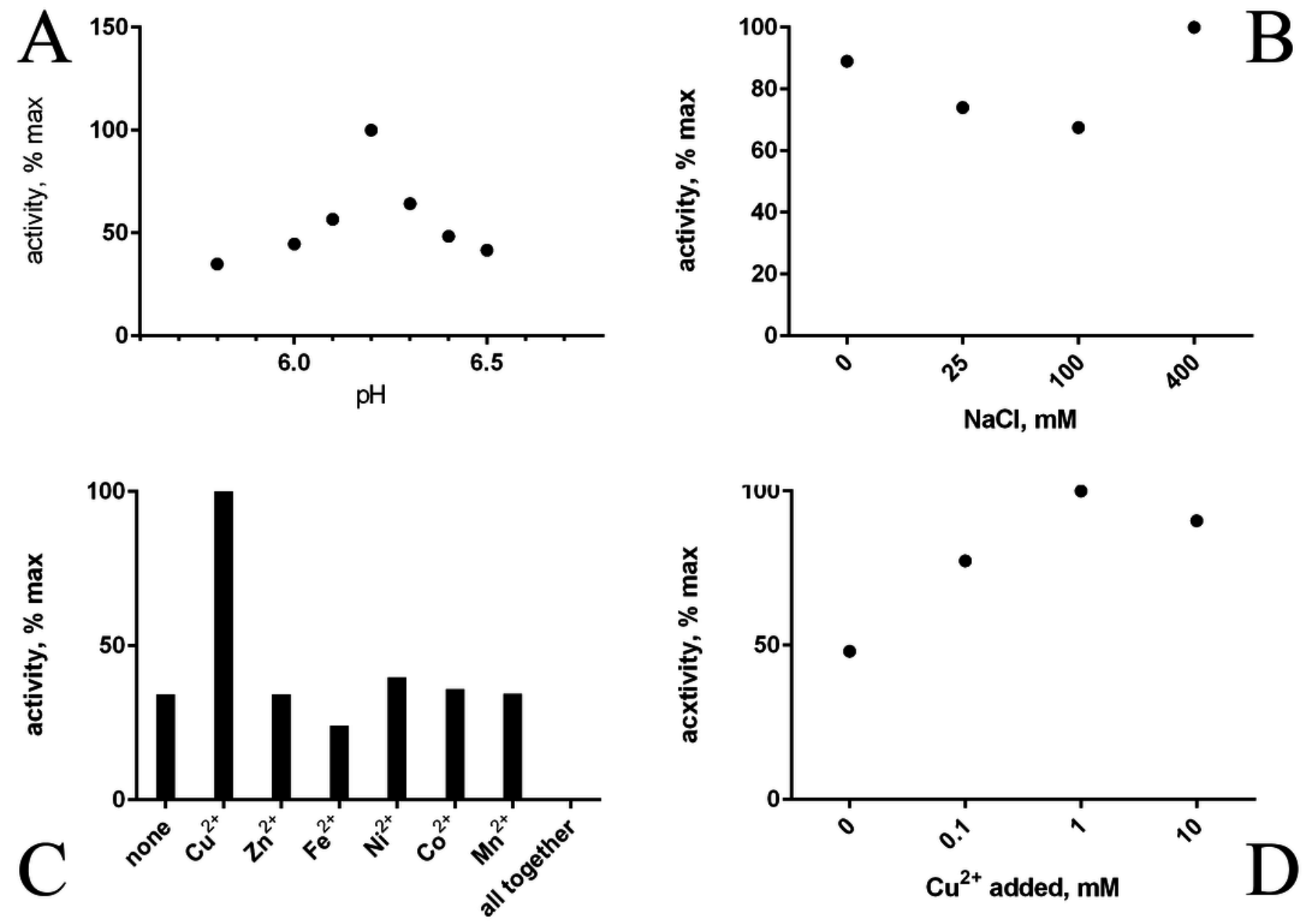
Figure 3

pH dependence of recombinant $H$. turkmenica lysyl oxidase.

In comparison with LOX from sheep aorta amine oxidase reaction rates were measured for HTU-QV protein if universal borate-phosphate-acetate buffer with histamine as the substrate.

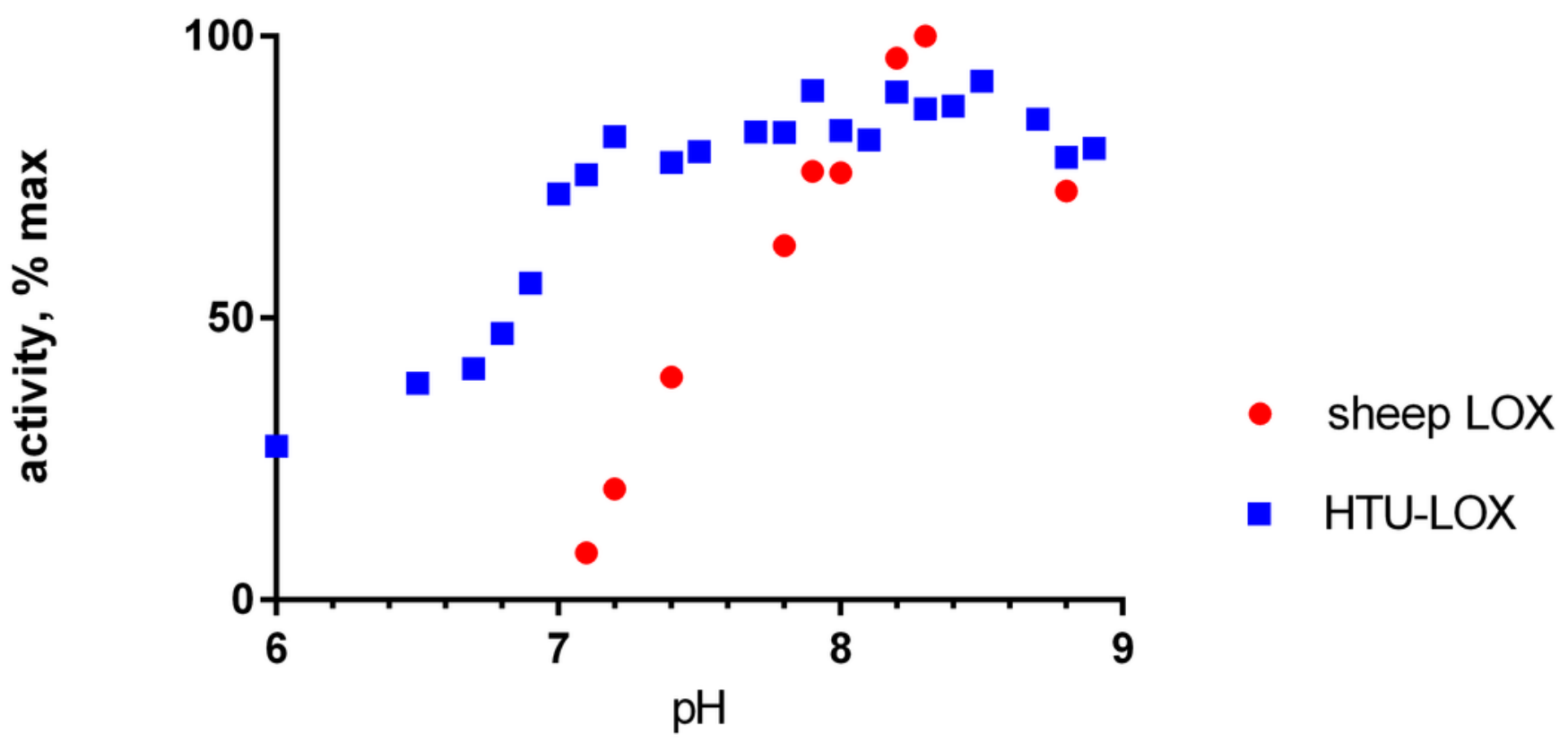




\section{Figure 4}

Immunoblotting detection of lysyl oxidase in $\mathrm{H}$. turkmenica cells with anti-HTU-LOX antibodies.

Chemiluminescence of bound HRP-labeled antibodies; positions of molecular weight markers on the left and in the middle. 1-3 - affinity purified antibodies against HTU-QV, the catalytic domain of LOX from $H$. turkmenica. 4-6 - negative control with rabbit serum against an unrelated antigen (Dmitriev et al, 2009). 1,2,4,5 - proteins of $H$. turkmenica grown to logphase (lanes 1 and 4 were loaded with three times more protein than lanes 2 and 5). 3,6 proteins of Halorubrum sp. VKK1262 (loading equal to lanes 2 and 5).



260 -

140 -

100 -

70 -

50 -

40 -
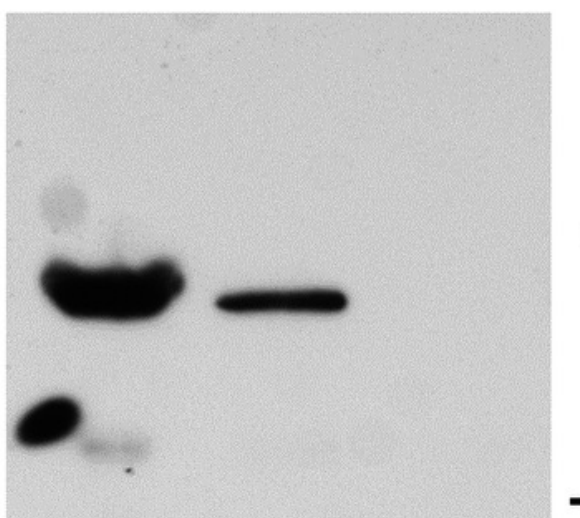

- 250 -

- 130 - 


\section{Figure 5}

\section{Multiple alignment of archaeal lysyl oxidases.}

Obtained using Muscle algorithm. (HaloterrigenalimiCola - Haloterrigena limicola, HaloterrigenaturCk - Haloterrigena turkmenica, NatronoCoCCusjeotgali - Natronococcus jeotgali, NitrosopumilussalariaDB31 and Nitrosopimulus - Nitrosopumilus sequnces. Yellow cysteine residues marked in yellow, red - LTQ-forming lysine and tyrosine, purple - three hyperconserved histidine residues necessary for the binding of $\mathrm{Cu}^{2+}$.

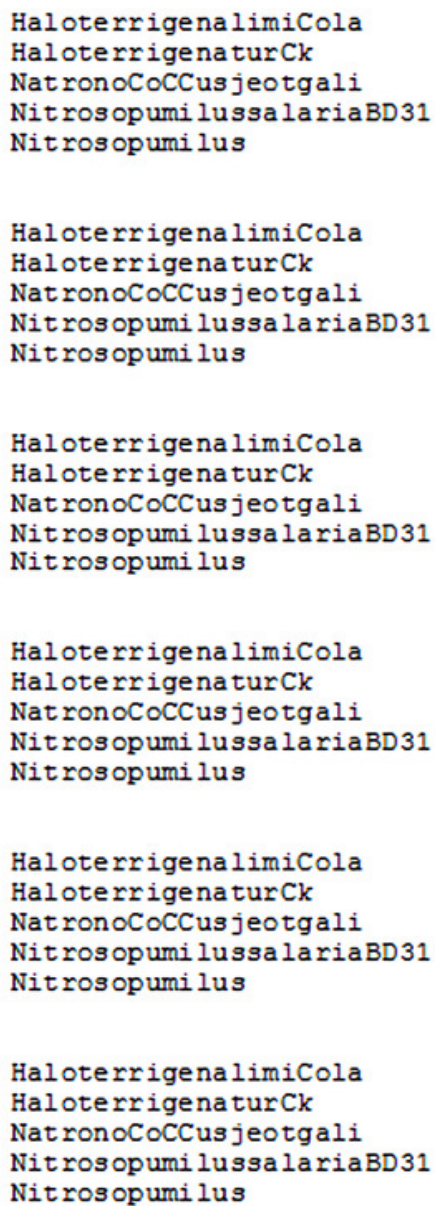

MKIKR IKGRKRAAAL IGVFL IVVAG IGI IT LGGVAVDN PF TVS DRSTDTPTTSE-SEGTT MI LNW IKERKRA TALVGVLL IVVAGVGM IT LGGVA.DN PF TVSDSSTDTSTTSG-SEDTA $----M K D R K R A$ TVLVG I IL IAVVGAGI IT LGDVTVNN PF TVNDSNTDTSTTSE-SEGTA ---MTYTKKIF RKTTL I PVLLAI--------GFMFTT PMLLDVAAAPGGNGNG-NGGST *: : . : . . . . .

DEGAT PADEENAATP PPTTVESD PKPS-----DDHVEDRT GVN FVPGVEN FNVST EVF DE NEEAT PVDEENSTT-PST-TESDSE PSDDQVEDDQVEDQP EVN FVPGVRN FDVSI EEFDE NEEAT PVDKENPAT-SSTPAESNSE PS-----DAQVEDKPEVN FVPGVRDFSI STEEFDE DE TT I PTNAL LP DVS PGVPKHLN IHNQ--------QQKE FLR FTNVWANLGP GT LEFEP ---SI PS DAL LP DIS PGVPKHLN IHNQ--------QQNE FLR FTNTWNNVGVGALEFEP : $*$ : . . . : . $\quad$ : : :.*. :...

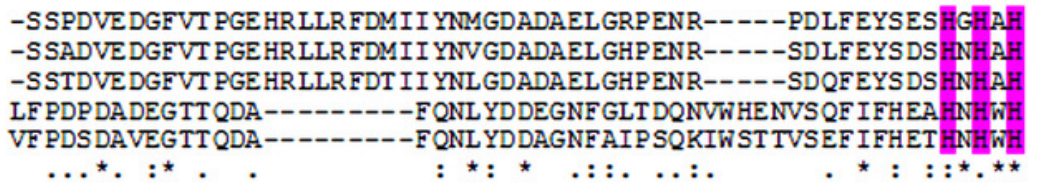

LKGFNNY ILL-DESGE---------RT GAVRRQT FCLRDLYQTRSTASSSPQ-- -FDC LKGFNKY KIL-DEAGN---------EMNA GKK QT FCLRDNFQTR SNASS SAK---FDC LKGFNKY ALF-DESGN---------EMDMGKRQT FCLRDDFQTRSNASSSAK---FNC IDNVGEFAVRAY DPNNP DVPGDIV--DDAASI KVGFCI TNVFKYNGEESPTSQRI YWDC ISDIGEFSIRSDDNGVPGEI AKNVNGDDVAAVKVG FCI ADVYKYNGDNSPTSQRVYWDC

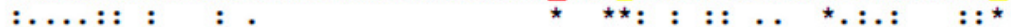

E--YQGI SAGWADEYDASLPGQY IVIDDLPDGEYTLQATTNAAGT I--NETCDGDNTVRV D--YQGI SAGWADVY PASLPGQY LVIDDLPDGE YT LQATTNAEGT I--DE KCDDDNTVRV D--YQGI SAGWA DVY PASLPGQYLVIDGLPDGEYT LHATTNAEGT I--DEKCDDDNTVRV EVGLQGI OPGWVDOYHOSVE GNE IN ITKVPNGT YF LTH TWNPANA FVDADNSNNVSWMKF EVGLQGI APGWADQYHQSVEGNE IN ITDLPNGT YF LVHKWNPANA FVDADVSNDESWMKF

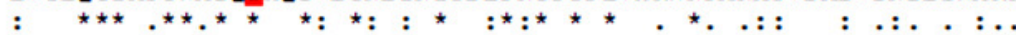

DL-------SINNDTVTVH TPQSHYVR PSAC------DL-------RINNDTVTVHSSQDDYVKPPSC-----DL-------RINNDTVTVL SSQEDHVKPSAC-

ELTDDGNGNR KINEI EGFAPECQDDDST PGICGDINKNS DLTDDGNGNR KIVEI EG FAPECQGDGST PGICGEINKNN : $\quad$ * : $\quad$ * $\quad$ * 


\section{Figure 6}

Multiple alignment of the conserved segments of catalytic domains from all lysyl oxidases representing different kingdoms.

Obtained using Muscle algorithm from consensus sequences of different taxa. ARCHAE Archaeal LOX sequences, DELTA - Deltaproteobacteria, FUNGI - fungal LOXes, ANIMA various animal LOXes, LOW - Mesomycetozoa and Orthonectida, short - LOX from Truepera radiovitrix, Deinococcus pimensis, Nitrospira nitrosa, and a few samples from Parcubacteria, BETA - Betaproteobacteria, Actinshort - Amycolatopsis mediterranei LOX and closest homologues, STREPTOM - LOX from Streptomyces, ACTINvar - other actinomycetal LOXes, BACIES - all other eubacterial LOXes. Yellow - cysteine residues marked in yellow; red - LTQforming lysine and tyrosine; purple - three hyperconserved histidine residues necessary for the binding of copper. 
ARCHEA

DELTA

FUNGI

ANIMA

LOW

BACIES

short

BETA

ACTINshort

ACTINvar

STREPTOM

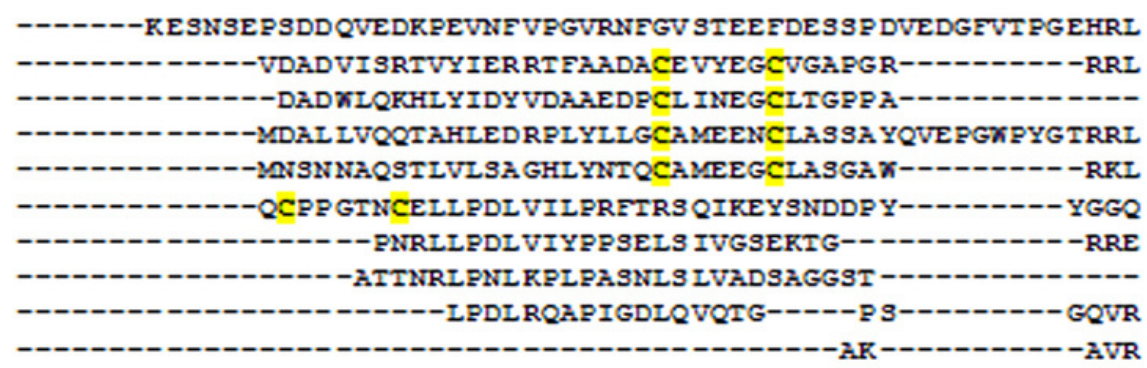

QAPAPALRANAKRFTRATVPNVPRPDIRSIPAYGITVSDGYEDVPG-----------KDY
ARCHEA

DELTA

FUNGI

ANIMA

LOW

BACIES

short

BETA

ACTINshort

ACTINvar

STREPTOM

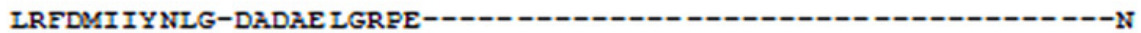
LRESVSIPNLG-SAAVI PPRE---0--

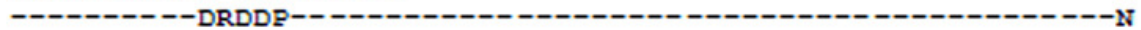
LRETARIXNRG-TADEI PR---1--

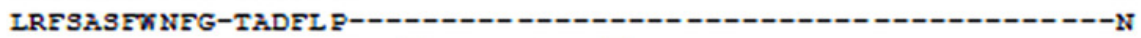
LREAATIANIG-DGPMETRGYCGTLGVVSNSICPDG SYPRQVLFQR IYSLRDFNLS SVDR IREATTVK NIGRSGPLE IIGTV------------DP ATNRTRVYQR IFARGGESAS---R LRENTTSXNRG-SGPIVIGAGA-----------VDT GSGRQQVFQRVELSNGGYFV---P LRETTSIVNV--DGPII IVAHR------------DSTDVPEAVVA I-QSDGSIADV--E LRETAAEX NAG-DGPII IYGRR------------DS ATDTMDVRQY FFDAKHGQVQR--Q LAFSANVKNAG-PARLVVDGER------------SPGRELUDAYQY FYDARGRQVGY--T
\end{abstract}

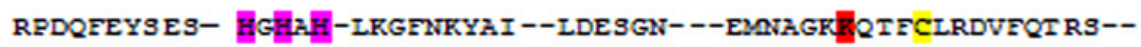
NPDI YVYDEC--HOHEH-IVNFASYEI--RDADNN----VVAVGRPQGFYIVD-MEPYC-NPPYKHKD TC-- HEFHWH-FTAYANYRL--ISANGS--EVVAQGHFWNGECLED-SICDE-PRHSKEKH AC--HCH H H HMEVEAHYDI--IDLNGT---KVAEGHF A SFCLED-TECDG-PDDGPEKHEC-- FWN PAGTNYYDNQPG TAGYFEYH PD-- HEFH H. VAGGFEKH PA--FWH TPASI YYE PADGHDE

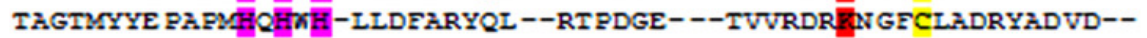

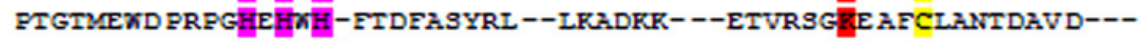
: $4+$ : + : $+4:$ :
ARCHEA

DELTA

FUNGI

ANIMA

LOW

BACIES

short

BETA

ACTINshort

ACTINvar

STREPTOM

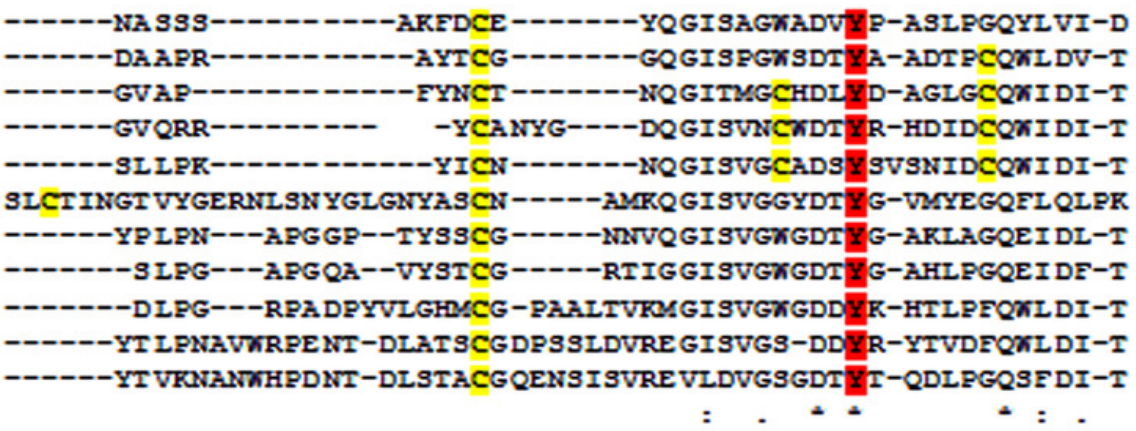

DI-------PDGEYTLQATTNAEGTIDERCDDDNTVRVDLRI---------------DV------PDGTYTLRVGVDTRDIVDEGDVHPNTVDVPVR--DLHLQPGY S PNTEYTLSVILNPEKAIPETDYSNNAA V--DV-------PPGNYILKVVVNPEFAVAESDFTMNAVRCNIRY---- - -

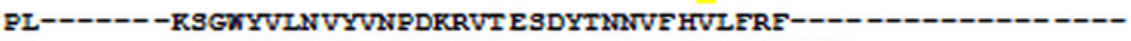


DV-------PDGRYLIR VEVDPEDRIEELDYDNNESVTFVEI-------------GN-------ADGTYQLR IVIDPNKVI I ESDESNNAS CVLISIRKPNTVTVLDSSGS CSTA GL-------PAGRYDLVNVADPDGALL EROYDANNAS KVDISVTSP------------HV-------PSGTYDLVNTVNPDRTI-ETSYDNSS SIAIVLGGT------------

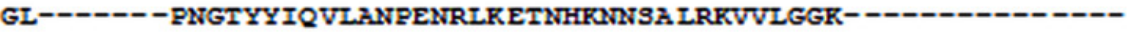

